\title{
Nickel-Catalyzed Enantioconvergent Coupling of Racemic Partners
}
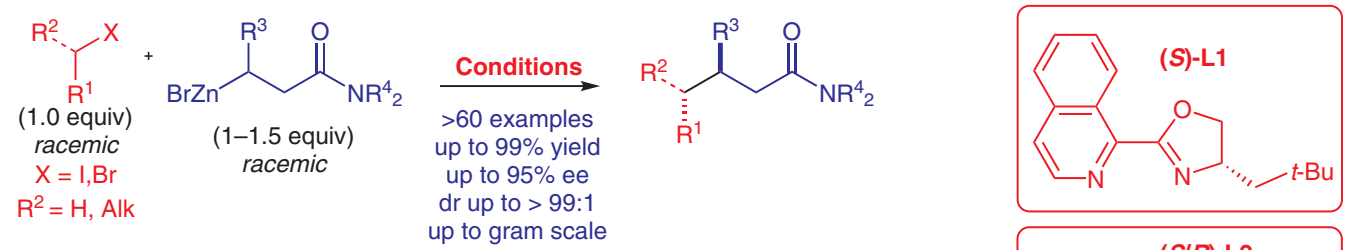

Conditions:

A) $\mathrm{NiCl}_{2}$.glyme (10 mol\%), (S)-L1 (12 mol\%), $\mathrm{Ph}_{2} \mathrm{P}\left(\mathrm{CH}_{2}\right)_{5} \mathrm{PPh}_{2}(10 \mathrm{~mol} \%), \mathrm{THF},-5^{\circ} \mathrm{C}$

B) $\mathrm{NiCl}_{2} \cdot$ glyme (12 mol\%), (S)-L1 (15 mol\%), $\mathrm{Ph}_{2} \mathrm{P}\left(\mathrm{CH}_{2}\right)_{5} \mathrm{PPh}_{2}(9 \mathrm{~mol} \%), \mathrm{THF}, 5^{\circ} \mathrm{C}$

C) $\mathrm{NiBr}_{2}$.glyme (10 mol\%), (S/R)-L2 (13 mol\%), LiCl (1.2 equiv), THF, r.t.
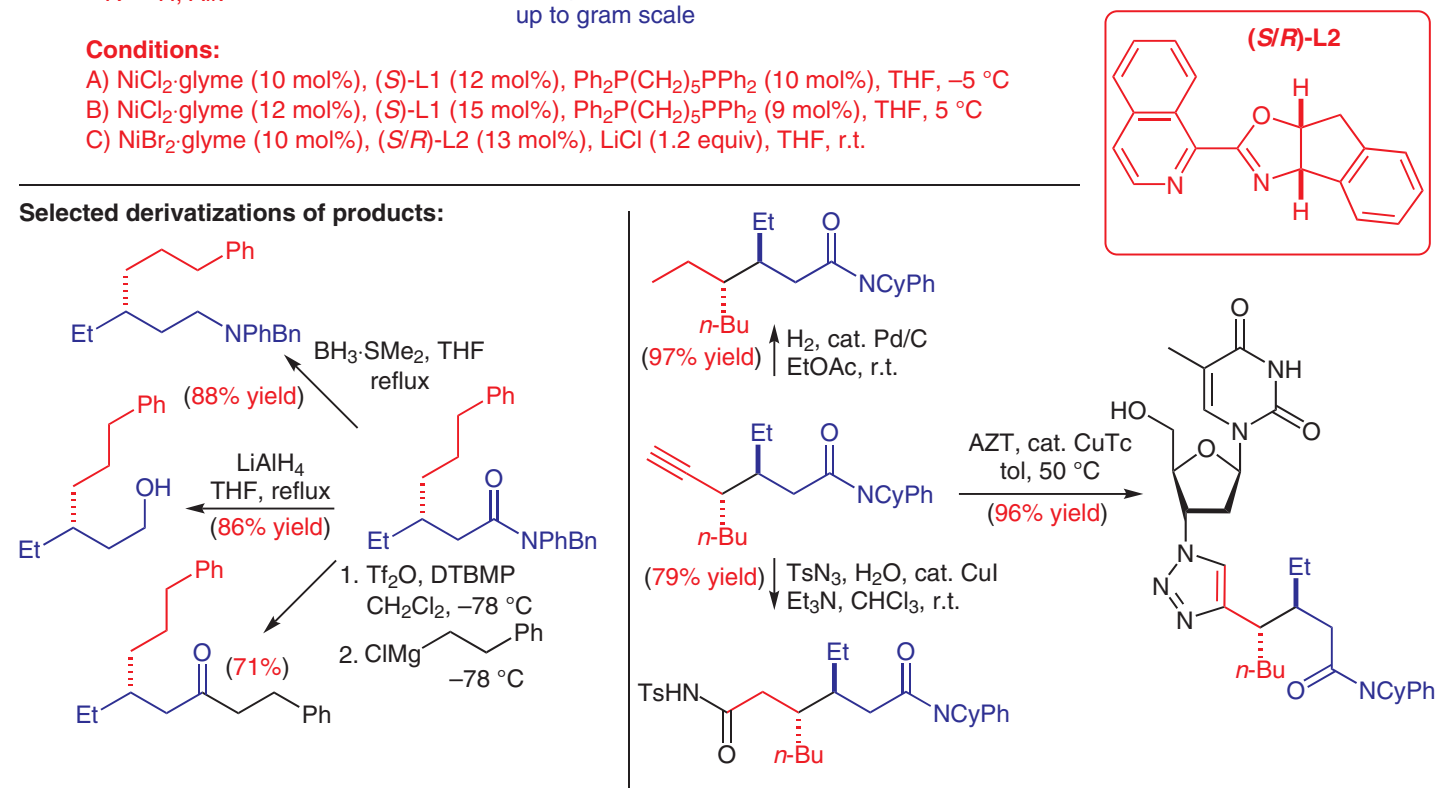

\section{Key words}

nickel catalysis

enantioconvergent coupling

alkyl nucleophiles

$s p^{3}-s p^{3}$ bond

\section{Synfact of the Month}

Significance: Fu and co-workers report a nickelcatalyzed doubly enantioconvergent alkyl-alkyl coupling of racemic partners that proceeds with unprecedented selectivity. The authors employed a chiral nickel catalytic system that generates the product as a single stereoisomer from racemic propargylic halides and racemic $\beta$-zincated amides.
Comment: The authors propose that the enantioconvergence of the starting materials is facilitated by a radical intermediate arising from both starting materials. The presence of radical intermediates was inferred by the TEMPO adducts formed from both the electrophile and nucleophile partners in the mechanistic study. 